\title{
The Phosphoprotein Gene from Canine Distemper Virus as Target in Viral Detection
}

\section{Mateo F, Cespedes PF and Navarro C* \\ Department of Animal Preventive Medicine, University of Chile, Chile}

*Corresponding author: Carlos 0 Navarro, Department of Animal Preventive Medicine, University of Chile, Vespucio 3121 M44 Macul, Chile, Tel: 0963941502; Email: canavarr@uchile.cl

\section{Investigation Paper}

Volume 2 Issue 6

Received Date: November 04, 2019

Published Date: November 25, 2019

DOI: $10.23880 /$ izab-16000186

\section{Abstract}

The Canine Distemper Virus (CDV) is the causal agent of a severe multisystem disease of dogs and other carnivorous species. Canine Distemper (CD) is a highly contagious disease that can reach high morbidity and mortality.

The wide spectrum of clinical signs makes the clinical diagnosis of the disease difficult and requires confirmation through laboratory tests. The molecular detection of CDV has advantages in the diagnosis of the disease. In the present work, the technique of Polymerase Chain Reaction-nested version-previous reverse transcription (n-RT-PCR) for the detection of the viral phosphoprotein gene (P gene) was implemented. As positive controls, RNA from vaccinal strains and samples positive to other CDV genes was used by RT-PCR. As negative controls, RNA was used from dog samples without clinical signs of the disease and as control of reactants, nuclease-free water.

Subsequently, the technique was used in 10 field samples of dogs with clinical suspicion of the disease, detecting the viral genome in $100 \%$ of the samples analyzed, generating a band close to $430 \mathrm{bp}$, corresponding to the targeted target sequence of the phosphoprotein gene of the CDV. The amplification products were characterized by their great intensity and sharpness, not observing nonspecific amplification bands.

Finally, the sequencing of the products obtained from the n-RT-PCR was performed, obtaining a high percentage of nucleotide identity with respect to the nucleotide sequences of the $\mathrm{P}$ gene stored in the GenBank®. This allowed establishing that the n-RT-PCR implemented in this Title Memory allows the detection of CDV.

The implementation of this technique will allow the antemortem detection of the virus and, therefore, facilitate the diagnosis and early treatment of the disease.

Keywords: Canine Distemper Virus; Phosphoprotein; P Gene; N-RT-PCR

Abbreviations: CDV: Canine Distemper Virus; CD: Canine Distemper; n-RT-PCR: Reaction-Nested VersionPrevious Reverse Transcription; ELISA: Enzyme-Linked
Immunosorbent Assay; CSF: Cerebro Spinal Fluid; RT: Room Temperature; NIP: Nucleotide Identity Percentage. 


\section{International Journal of Zoology and Animal Biology}

\section{Introduction}

The Canine Distemper (CD) is one of the most important viral diseases in wild and domestic canids of the world. However, it also affects a wide range of animals from diverse families of mammals such as Mustelidae, Procyonidae, Ursidae, Viverridae, Hyaenidae and Felidae. It can drastically compromise the conservation of threatened species due to its high lethality $[1,2]$.

$\mathrm{CD}$ is a serious and highly contagious disease that mainly affects the respiratory, nervous and gastrointestinal systems. Dogs are infected both by secretions as well as by aerosols from exposure to respiratory exudates and fluids of the infected animal that eliminates the environment along with the viral particles. The incubation period of the virus is 6 to 9 days, but the signs will be observed after 2 to 3 weeks of being exposed to the infection. Infected dogs can excrete the virus for a maximum of 60 to 90 days post-infection [1,3]. Dogs between 3 and 6 months of age have a higher prevalence of infection with CDV, which correlates with the loss of maternal antibodies [3]. However, in susceptible populations, the disease affects dogs of all [4].

The first pathogenic event is the local replication of the virus in the upper respiratory tract or in the conjunctival epithelium. After multiplication in the regional lymph nodes, the virus enters the bloodstream transported by lymphocytes, to produce the first viraemia. The virus spreads, because of the viremia, to all the lymphoid organs (spleen, thymus, among others). At this time of infection, if there is a good immunological response from the animal, the clinical signs are mild, and the virus does not spread to the rest of the body. On the other hand, if the immune response is weak or delayed, the CDV invades the entire organism, mainly the intestinal, urogenital, respiratory and skin epithelia, and even the central nervous system [5].

\section{Clinical Presentations}

In dogs, clinical presentations can vary from acute to chronic systemic conditions, with high mortality rates. Also, the severity of clinical signs observed depends on the virulence of the infecting virus, environmental conditions, as well as the age of the host and its immune status [3]. The virus replicates in lymphatic tissues of the respiratory tract and subsequently reaches various organs, including the cells of the lower respiratory tract and gastrointestinal tract, the lymphoid organs, the urinary bladder and the nervous system. This can result in either a subclinical infection or a presentation of respiratory, ocular, gastrointestinal, neurological, and cutaneous signs or lesions that appear simultaneously or sequentially. Nervous signs may be present in the chronic form of the $\mathrm{CD}$ along with other manifestations, or, nervous signs may be presented independently [6].

Systemic signs include apathy, anorexia, dehydration, fever, and oculonasal serous discharge. The nasal discharge often progresses to mucopurulent, with cough and dyspnea. Nervous system signs are often observed between one and three weeks after the affected animals recover systemically from CDV. However, nervous signs can also occur simultaneously with systemic disease or, less commonly, months after infection [1].

\section{Etiological Agent: Taxonomy and Viral Characteristics}

Canine Distemper was first described in Spain in 1791 and, the virus, isolated by Henri Carré in 1905. In Chile, although it is unknown when the first cases arose, it is known that this disease has been present for years, being its presence suggested in 1994, when the isolation of the virus was reported from a clinically ill puppy that showed respiratory and nervous signs [7]. The CDV belongs to the Mononegavirales order, Paramyxoviridae family, Morbillivirus genus, and is closely related to other morbilliviruses such as the measles virus in humans, the rinderpest virus and the plague of small ruminants, among others. The CDV, besides infecting the terrestrial carnivores of the family Canidae (dogs, wolves, coyotes and jackals), infects other mammals including species of the families Mustelidae (ferret, mink and badger), Procyonidae (raccoon and coati), Ursidae (bears), Viverridae (civet and genet), Hyaenidae (hyena), and Felidae (wild cats). As well two It affects marine carnivores such as seals and cetaceans like the dolphin $[1,8,9]$.

The viral genome consists of non-segmented RNA, single-stranded and negative polarity, it has an envelope and a size between 150 and $300 \mathrm{~nm}$ in diameter [5,6]. The CDV genome is approximately 15,700 nucleotides in length and contains six genes that code for virion proteins. The matrix protein (M gene, $1 \mathrm{~kb}$ ) plays a fundamental role in the morphology and assembly of the virion. The fusion protein ( $\mathrm{F}$ gene, $1.9 \mathrm{~kb}$ ), is a glycoprotein that is essential for mediating the fusion between the viral particle and the host cell membrane, providing the virus with the necessary mechanism to move from one cell to another. Hemagglutinin (gene H, 1.8 


\section{International Journal of Zoology and Animal Biology}

$\mathrm{kb}$ ), is the glycoprotein responsible for viral adhesion to the host cell. The nucleocapsid ( $\mathrm{N}$ gene, $1.5 \mathrm{~kb}$ ) is the protein responsible for the protection of viral RNA. Polymerase (L gene, $6.5 \mathrm{~kb}$ ), and phosphoprotein (P gene, $1.5 \mathrm{~kb}$ ) are the proteins that form a functional polymerase complex and are responsible for replication of viral RNA $[5,6]$.

The $\mathrm{P}$ gene of the CDV is a highly conserved gene of the virus [10] and, as in other viruses belonging to the Paramyxoviridae family, it is polycistronic, it encodes three different proteins $\mathrm{P}, \mathrm{V}$ and $\mathrm{C}$ [11-13]. Protein P is essential for viral replication, is synthesized in excess in infected cells, and shows a high turnover rate, presenting transient functions during assembly of the nucleocapsid and RNA synthesis. On the other hand, proteins $\mathrm{C}$ and $\mathrm{V}$ are considered non-essential for replication. Protein $\mathrm{P}$ bound to $\mathrm{L}$, integrates the polymerase complex responsible for RNA synthesis (transcription and replication) $[12,14]$.

\section{Diagnosis}

The wide spectrum of clinical signs makes diagnosis difficult and requires confirmation through laboratory tests $[1,6]$. Due to the above, there are several techniques for the diagnosis of $\mathrm{CD}$, among these is the histological diagnosis, in which intranuclear and intracytoplasmic inclusion bodies are revealed in numerous tissues. Serological methods, such as enzyme-linked immunosorbent assay (ELISA) and seroneutralization assays, seek the detection of specific antibodies for CDV. In the analysis of cerebrosnipal fluid (CSF) it is possible to observe an increase in anti-CDV immunoglobulin titers (IgG and IgM) that are highly suggestive of CDV infection, in addition to an increase in protein concentration $(>25$ $\mathrm{mg} / \mathrm{dL}$ ) and cell count (10 cells/mL with a predominance of lymphocytes) that are observed in inflammatory forms of CDV, as in an encephalomyelitis [1,6]. All these techniques have as a disadvantage the diagnosis of false positives, if post immunization with vaccine is carried out. While the diagnosis of QOL by virus isolation, despite being a definitive diagnosis, is very slow to perform [6]. In summary, none of the methods meets the requirements of being a rapid, sensitive and specific detection assay for CDV [15].

\section{Polymerase Chain Reaction (PCR)}

The PCR technique was developed in ' 80 s, since then, it has revolutionized molecular genetics, making possible the study of a wide range of genes. It has been used in multiple areas where the immense potential of PCR to amplify minimal amounts of DNA (or RNA) has been particularly attractive [16]. Recently, it has been successfully applied for the detection of nucleic acid, since it is a highly specific, rapid and sensitive method for the antemortem diagnosis of CDV infection in dogs, independently of the presentation of CDV, of the humoral immune response, and distribution of the viral antigen $[1,15,17]$.

Generally, for the detection of CDV by RT-PCR, regions conserved within the viral genome, such as the gene of the nucleocapsid protein ( $\mathrm{N}$ gene), are used as main targets for amplification [15,17]. However, in our Faculty, previously, two memories of titles based on the use of CDV RT-PCR have been developed [18,19], focused on the gene of hemagglutinin (gene $\mathrm{H}$ ), which presents greater antigenic and genetic variation among the CDV genes. On the other hand, we developed an RT-PCR based on the detection of the nucleocapsid protein gene, obtaining improvements in the detection of CDV compared to the two previous experiences [20].

Considering the above background, in this work proposal was raised to establish a method of molecular diagnosis using the technique of nested RT-PCR for the detection of the gene of the phosphoprotein (gene P) of the CDV, highly conserved gene, in blood samples dogs. This was corroborated by the detection of a DNA fragment of approximately 430 base pairs and its subsequent verification of the identity of the $P$ gene of the $\mathrm{CDV}$ in the analyzed DNA fragments

\section{Material and Methods}

The experimental work was carried out in the Virology and Microbiology laboratories of the Department of Animal Preventive Medicine of the Faculty of Veterinary and Animal Sciences of the University of Chile, under funding from the FIV Project 121014019102010.

\section{Samples and Controls}

For the implementation of the nested RT-PCR, RNA extracted from positive samples to the detection of the CDV H gene by RT-PCR [18,19] and, subsequently, positive to RT-PCR were used as positive controls. Detection of the N gene [20] (Table 1) and RNA extracted from three vaccines containing live attenuated CDV viruses: "Nobivac $®$ Puppy DP", "Canigen ${ }^{\circ}$ MHA2PPi /L" and "Vanguard Plus 5/CV- L ", of different strains of the virus: Onderstepoort, Lederle and Snyder Hill, respectively. As a negative control, RNA extracted from 
blood was used with anticoagulant (EDTA) from a dog without clinical signs of the disease, without a risk history and without vaccination (uninfected animal) and as reagent control: nuclease-free water.

\begin{tabular}{|c|c|c|c|c|c|c|}
\hline Canine & Race & Age & Sex & Vaccination against CDV & RT-PCR (gen H) & RT-PCR (gen N) \\
\hline A & half-blood & $1,5 \mathrm{y}$ & $\mathrm{M}$ & yes & positive & positive \\
\hline B & half-blood & $2 \mathrm{y}$ & $\mathrm{M}$ & no & positive & positive \\
\hline C & half-blood & $1,5 \mathrm{y}$ & $\mathrm{M}$ & yes & positive & positive \\
\hline D & Boxer & $3 \mathrm{y}$ & $\mathrm{M}$ & yes & positive & positive \\
\hline E & Labrador & $1 \mathrm{y}$ & $\mathrm{M}$ & yes & positive & positive \\
\hline F & Boxer & $2 \mathrm{y}$ & $\mathrm{M}$ & no & positive & positive \\
\hline G & half-blood & $2,5 \mathrm{y}$ & $\mathrm{M}$ & yes & positive & positive \\
\hline H & half-blood & $1 \mathrm{y}$ & $\mathrm{M}$ & yes & positive & positive \\
\hline I & Labrador & $1,5 \mathrm{y}$ & $\mathrm{M}$ & yes & positive & positive \\
\hline J & half-blood & $3 \mathrm{y}$ & $\mathrm{M}$ & yes & positive & positive \\
\hline
\end{tabular}

Table 1: Classification of blood samples from dogs with clinical signs of CD and classified according to race, age, sex, vaccination status against CDV and result to RT-PCR for gene $\mathrm{H}$ and gene N [18-20].

Thus, once the n-RT-PCR protocol was established, 10 peripheral blood samples with anticoagulant from dogs that had CD signs, some with CDV positive serology (Table
2), were included in the study. Different veterinary clinics of Santiago. These samples were previously submitted to RT-PCR for $\mathrm{H}$ gene and $\mathrm{N}$ gene, yielding different results.

\begin{tabular}{|c|c|c|c|c|c|c|c|}
\hline Canine & Race & Age & Sex & Vaccination against CDV & IgM titles & RT-PCR (gen H) & RT-PCR (gen N) \\
\hline 1 & half-blood & $2 \mathrm{y}$ & $\mathrm{H}$ & yes & $1: 40$ & Negative & positive \\
\hline 2 & half-blood & $1 \mathrm{y}$ & $\mathrm{M}$ & No & $1: 80$ & Negative & positive \\
\hline 3 & Bull Terrier & $2 \mathrm{y}$ & $\mathrm{H}$ & yes & $1: 80$ & Negative & positive \\
\hline 4 & half-blood & $1 \mathrm{y}$ & $\mathrm{H}$ & yes & $1: 80$ & Negative & positive \\
\hline 5 & half-blood & $3 \mathrm{y}$ & $\mathrm{H}$ & No & $1: 40$ & Negative & positive \\
\hline 6 & half-blood & $3,5 \mathrm{y}$ & $\mathrm{M}$ & No & - & Negative & positive \\
\hline 7 & Boxer & $2 \mathrm{y}$ & $\mathrm{M}$ & & $1: 40$ & Negative & positive \\
\hline 8 & half-blood & $9 \mathrm{~m}$ & $\mathrm{H}$ & No & $1: 80$ & Negative & positive \\
\hline 9 & half-blood & $1,5 \mathrm{y}$ & $\mathrm{H}$ & No & $1: 20$ & Negative & positive \\
\hline 10 & half-blood & $1 \mathrm{y}$ & $\mathrm{M}$ & yes & $1: 80$ & Negative & Negative \\
\hline
\end{tabular}

Table 2: Classification of blood samples from dogs with clinical signs of CD and classified according to race, age, sex, vaccination status against CDV, IgM titles and result to RT-PCR for gene $\mathrm{H}$ and gene $\mathrm{N}[19,20]$.

\section{Detection of the Phosphoprotein Gene (P Gene) of CDV by N-RT-PCR}

Viral RNA extraction: RNA extraction was carried out using the TRIZOL $®$ LS extraction kit (Invitrogen $\AA$ ), whose procedure was carried out at room temperature (RT). $0.75 \mathrm{~mL}$ of reagent was mixed with $0.25 \mathrm{~mL}$ of the sample, to lyse suspended cells, passing the suspension several times through a pipette. Then, $0.2 \mathrm{~mL}$ of chloroform was added, and the samples were shaken for
15 seconds. They were incubated at RT for 15 minutes and centrifuged at $12,000 \mathrm{xg}$ for 15 minutes at $4^{\circ} \mathrm{C}$. The aqueous phase was transferred to a new tube and $0.5 \mathrm{~mL}$ of isopropanol was added. It was incubated at RT for 10 minutes and then centrifuged at $12,000 \mathrm{xg}$ for 8 minutes. To the precipitate was added $75 \%$ ethanol $(1 \mathrm{~mL})$, vortexed and centrifuged at 7,500xg for 5 minutes at RT. The RNA precipitate was dried under vacuum for 5 minutes and resuspended in $100 \mathrm{uL}$ of nuclease-free 


\section{International Journal of Zoology and Animal Biology}

water. Finally, the RNA was incubated for 15 minutes at $50-60^{\circ} \mathrm{C}$ and maintained at $-20^{\circ} \mathrm{C}$ until its later use.

RT-PCR and n-RT-PCR: To carry out the technique, an Apollo thermocycler (CLP, USA) of 96 wells of $0.2 \mathrm{~mL}$ was used.

Primers: Were used: CDV-1: 5GGATGTGGAGAACGCAATAC-3 and CDV-2: 5'-GGAG GTCTCTCAATAGTTGA-3`, which allow the amplification of 1069 base pairs (bp) (Rzezutka and Mizak, 2002). The second pair of CDV-A primers: 5' ATGTTTATGATCACAGCGGT-3` and CDV-B: 5'ATTGGGTTGCACCACTTGTC-3', allows the amplification of $429 \mathrm{bp}$ [21]. The primers were sent for its elaboration to the Bioscan Company.

Mix of the reaction: In the RT-PCR reaction, the CDV-1 and CDV-2 starters and the "SuperScript one step RT-PCR with platinum Taq" kit from Invitrogen ${ }^{\circledR}$ were used, following the manufacturer's instructions, which consists of $25 \mathrm{uL}$ of " $2 \mathrm{x}$ " Reaction Mix " $(0.4 \mathrm{mM}$ of each deoxyribonucleotide and $3.2 \mathrm{mM}$ of $\left.\mathrm{MgSO}_{4}\right), 2 \mathrm{uL}$ of" SuperScript. III RT/Platinum Taq Mix ", 2 uL of each primer and 19 uL of RNA annealing to reach a total volume of $50 \mathrm{uL}$. The first step was the reverse transcription that was performed at $42^{\circ} \mathrm{C}$ for 50 minutes and then an initial denaturation at $94^{\circ} \mathrm{C}$ for 2 minutes. Then, a PCR of 35 cycles (denaturation: $94^{\circ} \mathrm{C}$ for one minute, alignment: $50^{\circ} \mathrm{C}$ for 2 minutes, extension $72^{\circ} \mathrm{C}$ for 2 minutes) and a final elongation of $72^{\circ} \mathrm{C}$ for 6 minutes. For each sample from the RT-PCR, the n-PCR was performed in a tube containing a mixture of $11 \mathrm{uL}$ of Master Mix 2X (Fermentas $®$ ), 5 uL of the CDV-A splitter, $5 \mathrm{uL}$ of the CDV-B primer and $1 \mathrm{uL}$ of product (sample). It was incubated at $94^{\circ} \mathrm{C}$ for 2 minutes and then the amplification was carried out in 30 cycles with denaturation at $94^{\circ} \mathrm{C}$ for one minute, alignment at $55^{\circ} \mathrm{C}$ for one minute and elongation at $72^{\circ} \mathrm{C}$ for one minute. The final elongation was performed at $72^{\circ} \mathrm{C}$ for 6 minutes.

Visualization of the amplified products: It was performed by electrophoresis in $2 \%$ agarose gel. The product of each PCR was mixed with a commercial loading product (Fermentas $®$ ), which contains glycerol to give density to the sample and bromophenol blue, to check the migration of the DNA bands. Electrophoresis was performed at $90 \mathrm{~V}$ for 45 minutes. After the electrophoresis, the incubation was carried out with ethidium bromide (BE, $0.5 \mathrm{ug} / \mathrm{mL}$ ) for 40 minutes and visualized under ultraviolet light in a trans illuminator, to be photographed later.

\section{Determination of the Nucleotide Identity of the Amplified Fragment}

Sequencing: To send the positive samples to the n-RTPCR to be sequenced, the samples of which the lineage was known according to the $\mathrm{H}$ gene were chosen [19]. Thus, only two samples were sent to be sequenced and correspond to sample F (CDV / FMR1) and sample H (CDV / FMR2), obtained from dogs of different ages, sex and vaccination status (Table $\mathrm{n}$-1). These samples were purified through the kit "HiYield Gel/PCR DNA Fragments Extraction Kit" (RBC Bioscience $®$ ), according to the manufacturer's instructions, and sent in triplicate, to the Sequencing Center of the company Genytec Ltda.

Nucleotide identity Percentage (NIP): The sequences delivered by Genytec Ltd. were aligned to obtain a consensus sequence through the online program of free access Clustal $\Omega$. The consensus sequence was entered into the BLAST sequence alignment computer program, to know its nucleotide identity.

Analysis of results: A positive sample was considered that after the nested RT-PCR originated a fragment of DNA of approximately 430 base pairs and that after the analysis with the BLAST program its nucleotide identity corresponded to CDV, with a respective NIP greater than or equal to $80 \%(\mathrm{NIP} \geq 80 \%)$.

Biosafety measures: To carry out the laboratory work, safety measures were adopted according to the biosafety levels established for the Microbiology and Animal Virology laboratories. These consist, mainly, in the use of clean and sterile material, use of white apron and gloves, both in the preparation of PCR mixtures and in the incubation of the gel in $\mathrm{BE}$. On the other hand, the visualization of the amplified products, involving the use of a UV light transilluminator, required the use of an acrylic plate and glasses with UV filter, the latter, to protect the vision of the observer. Finally, the gel was incinerated, since BE has mutagenic properties.

\section{Results}

\section{Detection of the P Gene of CDV by Nested RT- PCR in Control Samples}

The RT-PCR reaction allowed to observe a broad and clear band, for two of the three commercial vaccines (about to $1100 \mathrm{bp}$ ); the Vanguard Plus 5/CV-L vaccine does not generate visible band. On the other hand, in the nested RT-PCR, it was observed that the three vaccines formed a DNA fragment of the expected size (about to 430 


\section{International Journal of Zoology and Animal Biology}

bp). In both reactions no nonspecific bands were observed (Figure 1).

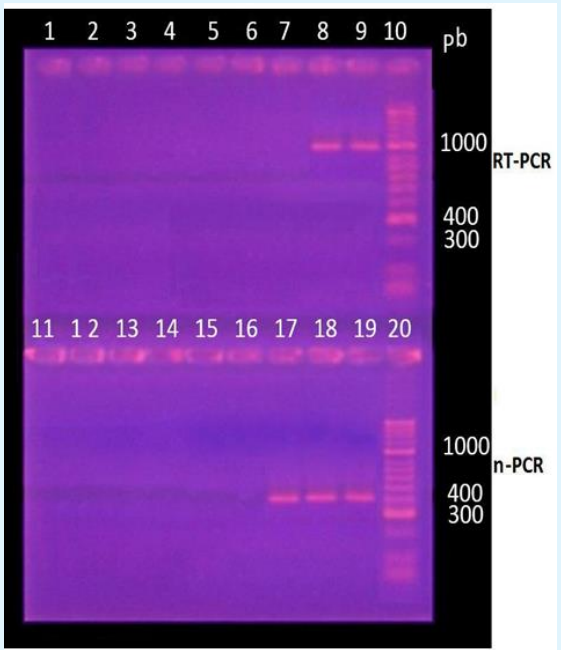

Figure 1: Detection of the phosphoprotein gene by RT-PCR. Visualization of products amplified by nested RT-PCR by electrophoresis in 2\% agarose gel in TAE buffer and subsequent incubation in ethidium bromide. Lanes 1, 2, 11 and 12: control of reagents (nuclease-free water duplicates). Lane 3, 4, 13, 14: negative control (uninfected dog, duplicate); Lane 5.6, 15.16: Control of reagents. Lane 7, 17: Snyder Hill Strain (Vanguard Plus 5 / L4 CV). Lane 8, 18: Lederle strain (Canigen ${ }$ MHA2PPi / L). Lane 9 and 19: Ondersterpoort strain (Nobivac®Puppy DP). Lane 10 and 20: MM, molecular size marker (50-2000 bp, Bioline $®)$.

When performing the RT-PCR in the 10 control samples positive for the $\mathrm{H}$ gene and the $\mathrm{N}$ gene (Table 1), it was observed that $100 \%$ of these samples resulted in clear and wide bands, close to $1100 \mathrm{bp}$. When performing the n-RT-PCR, intense bands close to 430 base pairs were observed in $100 \%$ of the samples (Figure 2).

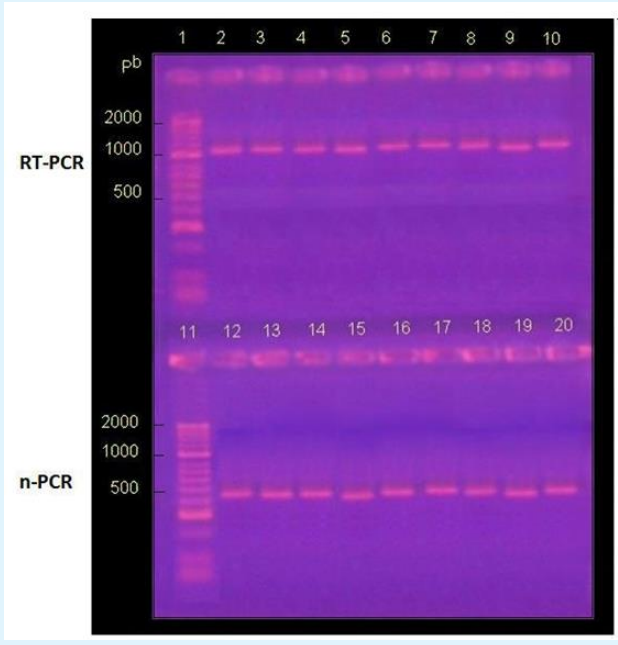

Figure 2: Detection of the Phosphoprotein gene by RT-PCR. Visualization of products amplified by nested RT-PCR by electrophoresis in 2\% agarose gel in TAE buffer and subsequent incubation in ethidium bromide. Lanes 1 and 11: MM, molecular size marker (50-2000 bp, Bioline ${ }^{\circledR}$ ). Lanes 2 to 10 and 12 to 20 correspond to positive controls of viral RNA from national isolates (Table 1). 


\section{Detection of the P Gene by N-RT-PCR in Samples Suspected of CDV}

The 10 samples of dogs suspected of CD (Table no2), were submitted to the nested RT-PCR for the P gene of
$\mathrm{CDV}$, and when the products were visualized, it was observed that the 10 samples (100\% of the samples) show a band of about 430 base pairs of different visualization quality (Figure 3).

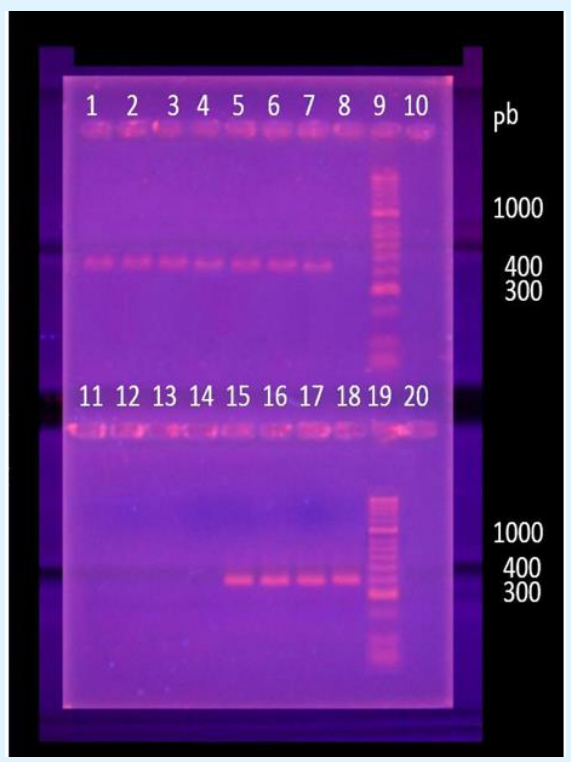

Figure 3: Detection of the phosphoprotein gene by nested RT-PCR. Visualization of products amplified by nested RTPCR by electrophoresis in $2 \%$ agarose gel in TAE buffer and subsequent incubation in ethidium bromide. Lanes number 1 to 7 (canine 1 to 7 respectively according to table 2) and lanes 15, 16 and 17 (canine 8 to 10 respectively according to table 2) correspond to clinical samples analyzed previously for the hemagglutinin gene [19]. Lane 18 corresponds to the Snyder Hill strain (Vanguard Plus 5/L4 CV); lanes 8 and 11 correspond to reagent controls, while lane 12,13 and 14 (triplicate) correspond to negative control, dog not infected with the virus. Lanes 9 and 19 correspond to the molecular size marker (50-2000 bp, Bioline ${ }^{\circledR}$ ). Lanes 10 and 20 do not contain sample

\section{Determination of Nucleotide Identity with Respect to Genbank ${ }^{\circledR}$}

The amplified from two of the positive samples (corresponding to samples $\mathrm{F}$ and $\mathrm{H}$ of Table 1 ) were sent in triplicate to be sequenced to the Sequencing Center Genytec Ltda., Receiving three sequences of around 430 bp for each sample (Appendix 1). Then, a multiple alignment was carried out using the Clustal W program, to obtain a consensus sequence for each sample and thus make the comparison with the official GenBank $®$ data. The consensus sequences, obtained from the Clustal W program, were analyzed with the BLAST program, which gave values of nucleotide identity with respect to CDV between 87 to $90 \%$ for the CDV/FMR1 sequence and from $94 \%$ to $99 \%$ for the sequence CDV/FMR2 (Appendix 2).

\section{Discussion}

The diagnosis of DC is usually made based on the clinical signs and the history of the dogs. However, it is difficult to differentiate CD from other diseases such as kennel cough in the early stage and other viral pathologies produced by canine coronavirus or by the infectious canine hepatitis virus, for example. Most of the diagnostic methods that have been used have problems such as the delivery time of results and the cross-reaction in dogs with recent vaccination [1,6]. Thus, a rapid, sensitive and specific method for the detection of CDV is necessary.

In this context, the diagnosis of CDV can be made using molecular biology techniques and PCR, and its RT-PCR variant, is one of the most important contributions in the 


\section{International Journal of Zoology and Animal Biology}

diagnostic area, allowing faster and more specific procedures [15]. Thus, RT-PCR proves to be an effective tool for the diagnosis of canine distemper, having as an advantage the high sensitivity, in addition to the short delivery times of results, in comparison with other techniques $[10,15]$.

With the aim of detecting the Phosphoprotein gene of the causal agent of Canine Distemper and within the framework of this title report, the molecular technique of nested RT-PCR was used. This method allowed obtaining a DNA fragment of $430 \mathrm{bp}$ from RNA obtained from vaccine strains, from previously positive samples to the $H$ gene of CDV 13 and, later, positive to the $\mathrm{N}$ gene (positive controls) and field samples suspected of CDV infection. The bioinformatics analysis of the involved sequences allowed to corroborate the identity of the samples incorporated to this study. Although the results of the nRT-PCR with the positive samples (vaccines) were as expected (obtaining a band of around $430 \mathrm{bp}$, Figure 1), it was surprising to not obtain a visible fragment of around 1100 bp (to RT-PCR) in case of Vanguard Plus 5/CV-L vaccine strain. The above can be explained by a lower viral titer in the vaccine or by the presence of an inhibitor in these samples. This particularity is not considered a problem, because when performing the n-RT-PCR, the expected results are obtained. This same phenomenon was also observed when implementing the molecular diagnosis of Feline Herpes Virus in the past [22]. If we consider that there is amplification and that the experimental conditions do not allow us to visualize the generated fragment, a possible solution would involve a greater number of PCR cycles [18].

The n-RT-PCR amplification products obtained in this report were clearly visualized, not observing nonspecific amplification bands or DNA degradation in any case. It should be noted that $100 \%$ of the samples, of the positive controls and the three vaccine strains used generated a band close to $430 \mathrm{bp}$. In addition, both the sample used as a negative control (dog without clinical signs of the disease) and the control of reagents did not generate amplification, confirmed by the absence of bands in the visualization of the agarose gel. This would reflect a high specificity of the used primers $[10,21]$. Thus, the detection of the phosphoprotein gene, a highly conserved protein among the members of the Paramyxoviridae family [10], suggests that the choice of the phosphoprotein $\mathrm{P}$ gene as target to be detected by n-RT-PCR, must be considered at the time of the final choice of the best diagnostic method of the CDV. 14 The aforementioned can be supported by considering the confirmation of the nucleotide identity made to the DNA fragments obtained; since the high values of NIP reached effectively show that the amplified DNA fragment corresponds to the phosphoprotein gene (P gene) of the CDV. However, the choice of the best diagnostic method of QOL must necessarily consider other previous studies. Thus, in Chile and in the same laboratory, experiments have been conducted based on the detection of CDV by RT-PCR but focused on the detection of the hem agglutinin gene [18,19]. This glycoprotein is responsible for the generation of an immune response by the affected organism and, despite being commonly used for $\mathrm{CD}$ diagnosis $[5,6]$, the $\mathrm{H}$ gene is the which has greater variation, so it would not be the best choice for the diagnosis of the virus [18] but rather, to know the lineage to which the circulating virus would belong [19].

Although in both mentioned studies positive results are obtained in the detection of the virus, the techniques used would be less sensitive: on the one hand, it manages to detect the virus in $19 \%$ of the samples [18]or detects viral RNA in 7\% of the samples tested [19]. The above was tested by implementing a PCR for the $\mathrm{N}$ gene (a more conserved gene coding for the CDV viral nucleocapsid protein) as a detection target and using the same samples achieved $90 \%$ detection positive, suggesting a greater sensitivity than previous experiences [20]. Although it is not the same gene considered, the comparison is relevant because the RT-PCR used is the same: conventional.

Although RT-PCR is a sensitive technique, its sensitivity can be further increased by performing an nRT-PCR, since it comprises two rounds of amplification with different pairs of starters in each. First, a reaction is performed with the external primers to amplify a larger DNA region, which contains the target sequence. Then, this amplification product is used as a template for a second PCR with internal primers to amplify the specific region [23]. Likewise, it was observed that the sensitivity of the technique used in this title memory was increased when carrying out the second PCR reaction (n-PCR), because the sample obtained from the Vanguard Plus 5/L4 vaccine (Snyder Hill strain) that initially turned negative to RT-PCR, when performing the n-PCR demonstrated an amplicon close to $430 \mathrm{bp}$ (Figure 1). This was also observed by Rzezutka, et al. [10], who after performing a n-PCR to six samples that were negative to RT-PCR, these generated amplifications. In the results of this title report, when the n-RT-PCR technique was used, improvements in the detection of viral genetic material were observed, surpassing the technique [20]. 


\section{International Journal of Zoology and Animal Biology}

The high NIP obtained through the BLAST program in the two analyzed sequences (between 87 to $90 \%$ for the CDV/FMR1 sequence and from 94 to $99 \%$ for the CDV/FMR2 sequence) with respect to the first hundred results awarded by the program, allow showing that both amplified fragments correspond to CDV. However, there is a noticeable variation between the NIPs of both sequences. By aligning the two consensus sequences through the BLAST program, a NIP of $90 \%$ was obtained among them so there would be a $10 \%$ variation between these sequences (Appendix 2), this variation could be explained by the two sequences segregate for different lineages: lineage America 1 and European lineage [19].

Finally, the results of this study used RNA samples (positive controls) extracted more than a year before and stored at a temperature of $-20^{\circ} \mathrm{C}$, which is not the ideal temperature described in the literature to maintain the integrity of the genetic material [20]. The RNA of the virus can remain indefinitely active at $-70^{\circ} \mathrm{C}$ or lyophilized and can be kept active for about a month at $-10^{\circ} \mathrm{C}$ [24]. Despite this, the results show that the stability of the RNA was not affected by this factor. The results obtained in this report suggest that the molecular technique of nested RT-PCR for the CDV phosphoprotein gene is a fast and highly sensitive method, and that, therefore, it could be used for the antemortem diagnosis of CDV infection. The sensitivity and specificity of the n-RT-PCR protocol used in this title memory was corroborated with the $100 \%$ amplification of both controls positive, as of samples of suspicious dogs, as well as, to the no amplification in negative controls. However, to corroborate these parameters of the method developed in this title report, additional studies are required.

\section{Conclusion}

The nested RT-PCR technique implemented in this title memory, through the detection of the CDV phosphoprotein gene (P gene), was able to detect $100 \%$ of the samples used, both positive controls (vaccinal and positive samples) as samples of animals suspected of presenting the disease. The high NIP obtained allows indicating that the method used is specific for the detection of CDV.

\section{References}

1. Pardo ID, Johnson G, Kleiboeker S (2005) Phylogenetic characterization of canine distemper viruses detected in naturally infected dogs in North America. J Clin Microbiol 43(10): 5009-5017.
2. Beineke A, Baumgartner W, Wohlsein P (2015) Crossspecies transmission of canine distemper virus-an update. One Health 1: 49-59.

3. Greene G, Appel M, (1998) Canine Distemper Virus. In: Infectious Disease of the Dog and Cat. $2^{\text {nd }}(E d n$.$) ,$ Greene GE Saunders, Philadelphia PA pp: 1-22.

4. Johnson R, Glickman L, Emerick T, Patronek G (1995) Canine distemper infection in pet dogs: I. Surveillance in Indiana during a suspected outbreak. J Am Anim Hosp Assoc 31(3): 223-229.

5. Murphy F, Gibbs E, Horizinek M, Studdert M (1999a) Paramyxoviridae In: Veterinary Virology. $3^{\text {rd }}$ (Edn.), Academia Press, New York, USA pp: 411-428.

6. Elia G, Decaro N, Martella V, Cirone F, Lucente M, et al. (2006) Detection of canine distemper virus in dogs by real-time RT-PCR. J Virol Methods 136: 171-176.

7. Cerda L, Mathieu C, Quinteros G (1994) First isolation of canine distemper virus in Chile. XIV Pan American Congress of Veterinary Sciences. Acapulco, México.

8. Appel M (1978) Reversion to virulence of attenuated canine distemper virus in vivo and in vitro. J Gen Virol 41: 385-393.

9. Pozza M, Simonetti A, Esteves P, Rijsewijk F, Roehe P (2007) Detecção do vírus da cinomose canina por RTPCR utilizandose oligonucleotídeos para os genes da fosfoproteína, hemaglutinina e neuraminidase. Arq Bras Med Vet Zootec 59(5): 1154-1162.

10. Rzezutka A, Mizak B (2002) Application of N-PCR for diagnosis of distemper in dogs and fur animals. Vet Microbiol 88(1): 95-103.

11. Wakasa C, Iwatsuki $K$, Ohashi $K$, Nakamura K, Kai Ch (2000) Sequence analysis of the genes encoding the phosphoprotein of recent isolates of canine distemper virus in Japan. J Vet Med Sci 62(1): 97-101.

12. Vagnozzi A, Carrillo C (2006) Análisis comparativo del gen P de Rinderpest Virus (RPV). In Vet 8(1): 6791.

13. Sugai A, Kooriyama T, Sato H, Yoneda M, Ka Ch (2009) Epitope mapNIPg of canine distemper virus phosphoprotein by monoclonal antibodies. Microbiol Immunol 53: 667-674. 
14. Karlin D, Longhi S, Receveur V, Canard B (2002) The $\mathrm{N}$-terminal domain of the phosphoprotein of morbilliviruses belongs to the natively unfolded class of proteins. Virology 296(2): 251-262.

15. Frisk A, Konig M, Moritz A, Baumgärtner W (1999) Detection of canine distemper virus nucleoprotein RNA by reverse transcription-PCR using serum, whole blood, and cerebrospinal fluid from dogs with distemper. J Clin Microbiol 37: 3634-3643.

16. Murphy F, Gibbs E, Horizinek M, Studdert M (1999b) Laboratory diagnosis of viral diseases. In: Veterinary Virology. $3^{\text {rd }}$ (Edn.), Academia Press. New York, USA pp: 193-224.

17. López C (2012) Diagnóstico del Distemper Canino. In: Simposio Internacional de Actualización en Distemper. Santiago, Instituto Neurológico, Chile pp: 1-35.

18. Jara P, Céspedes PF, Navarro C (2018) Canine Distemper Virus detection based in Hemaglutinine Gene as target in Reverse Transcriptase-Polymerase Chain Reaction. Insights Vet Sci 2: 034-041.

19. Salas V, Pizarro J, Navarro C (2018) Phylogenetic analysis of canine distemper virus detected in Chile.
International Journal of Current Research 10: 7240272407.

20. Munoz C (2013) Molecular diagnosis of the canine distemper virus by polymerase chain reaction associated with reverse transcription of the viral nucleocapsid protein gene. Santiago, Chile pp: 27.

21. Barrett T, Visser I, Mamaev L, Goatley L, Van Bressem $\mathrm{M}$, et al. (1993) Dolphin and porpoise morbilliviruses are genetically distinct from phocine distemper virus. Virology 193(2): 1010-1012.

22. Macías P, Navarro C (2018) Molecular detection of feline herpesvirus by Polymerase Chain Reaction. Dairy and Vet Sci J 8(3): 555736.

23. Goode T, Ho W, O Connor T, Busteed S, Douglas S, et al. (2002) Nested RT-PCR. In: RT-PCR protocols. Methods in molecular biology. 2nd (Edn.), Human Press. Cork, Irlanda pp: 65-79.

24. Pérez S, Iturbe R, Saldívar E (1993) Characterization of the distemper virus (canine distemper) in cell cultures isolated from clinically ill animals. Veterinaria México 24 (1): 15-19. 